\title{
Changes in myocardial threshold. Physiologic and pharmacologic factors in patients with implanted pacemakers
}

\author{
Thomas A. Preston, M.D.* \\ Ross D. Fletcher, M.D.** \\ Benedict R. Lucchesi, Ph.D., M.D.*** \\ Richard D. Judge, M.D.**** \\ Ann Arbor, Mich.
}

$\mathrm{T}$ The purpose of this report is to point out certain physiologic and pharmacologic factors which are capable of causing measurable changes in the threshold energy requirements of the human heart. These studies were made possible by the development of simple, external methods for making repetitive measurements of myocardial threshold and interelectrode impedance in patients with implanted pacemakers ${ }^{1,2}$ of a certain type.t

Random determinations of threshold after implantation of a pacemaker have demonstrated that myocardial threshold in the human being is not a static quantity. On the contrary, it is highly variable, subject to spontaneous changes, as well as being significantly modified by certain common drugs. A rational application of hreshold analysis to the clinical care of patients, or the development of pacemaker technology, required as a bis: an : yste matic, controlled investigation of hators capable of modifying threshold. Our experience to date suggests that several factors affect threshold in at predictable way. The most important of these are the physiologic acts of exercise, enting, and sleeping. Steroids, sympathomimetic agents, and infusions of sodium, polassium, and solutions of potassium and insulin in glucose also had pronounced effects on electrical excitation. In presenting our findings to date, we would like to stress the importance of monitoring the dectrical threshold of the heart in patients who are being paced by artificial means. As technology improves and these patientr survive for longer periods, the various biologio factors involved in maintaining sustained responsiveness of the myocardium may assume greater importance.

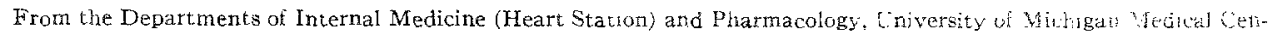
ter, Ann Arbot, Mich.

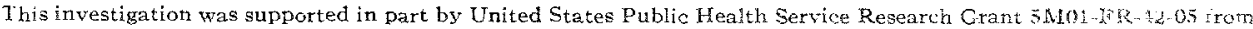
the Division of Research Facilities and Resources. Additional support was also received from a grant awarded by the Michigan Heart Association.

Received for publication Sept. 19, 1966.

* Teaching Associate, Department of Internal Medicine, University of Michigan. Reçuests for zeprints slould be atdressed to Dr. Preston, Úniversity Mospital, Lniversity of Michigan Medical Center, Ann Arbor, Mhit. 4810. **instructor, Department of Internal Medicine, University of Michigan.

***Assistant Professor, Department of Pharmacology, University of Michigan.

*****Associate Professor, Department of Internal Medicine, University of Michigan. 


\section{Methods and materials}

All patients in this study had complete heart block and permanently implanted artificial pacemakers of the type* which permit external measurement of myocardial threshold. These measurements can be performed only with this type of pacemaker. Patients ranged in age from 22 to 84 years, with a median of $661 / 2$ years. Six were males, and 8 were females. Bipolar myocardial electrodes were used exclusively. Measurements of threshold were made by using a threshold analyzer, a digital electronic counter (Model 5230 Beckman/Berkely EPUT \& Timer), and a cardiac monitor. Details of the threshold analyzer are reported elsewhere. ${ }^{2}$ Briefly, this instrument allows control of the rate and suppression of the energy output of the implanted pacemaker by introducing induction-coupled high-frequency signals which prevent the discharge of the output condenser.

To measure threshold with the threshold analyzer, the output of the implanted pacemaker is slowly reduccd by placing an induction coil directly over the implanted pacemaker, and capturing control of the implanted unit through signals coming from the threshold analyzer. We have arbitrarily defined threshold as the first point at which, with gradual reduction of pacemaker output, one or more stimuli of every ten fail to excite the heart, as detected by the absence of QRS complexes on the cardiac monitor. The energy output of the pacemaker at threshold can be accurately calculated by the pulse width initially and at threshold, as previously described. ${ }^{2}$ Threshold is measured at the inherent rate of the implanted pacemaker.

Interelectrode resistance can be measured by determination of pacemaker pulse width and rate, and by a comparison of these parameters with precalibrated values for the biologic range of interelectrode resistance. ${ }^{1}$

In order to be sure that measured changes in threshold were due to an administered agent and were not secondary to spontaneous physiologic changes, a set of strict criteria was established as follows: (1) The pacemaker must have been implanted for

*General Electric Company, Milwaukee, Wisconsin. at least 3 months in order to provide adequate time for the threshold to stabilize..$^{3-5}$ (2) Prior to and during the test, the patient may take no medications except that being tested. (3) Physical activity is limited. The patient is confined to bed throughout each test period, but is not allowed to fall asleep. Distracting activities, such as reading or knitting are encouraged. (4) All studies are performed in the fasting state. Water is allowed. During experiments which require more than 8 hours, a light meal is permitted. (5) Threshold must remain constant (less than a 5 per cent change) for a minimum of 30 minutes prior to the beginning of each experiment. Rarely, it is necessary to wait as long as 2 hours before this stabilization occurs. (6) After maximal change in threshold, due to the experimental procedure, the threshold level must return to within 10 per cent of the base-line level and remain there. (7) Administration of a drug cannot be made in a manner which itself might alter threshold. Intravenous medication which results in rapid changes is given through a needle inserted before the start of the test, with no demonstrated change in threshold due to venipuncture; or after stabilization of the threshold for 30 minutes after insertion of the needle. (8) The patient must not have a competing sinus rhythm or multiple ectopic ventricular beats.

All thresholds were measured as a per cent of available pacemaker energy, ${ }^{3-5}$ and changes due to drugs or physiologic activities were reported as the maximum per cent change from the base-line threshold. For example, if a patient's base-line threshold were 20 per cent (of available pacemaker energy), and the administration of a drug resulted in a maximal increase to 26 per cent, this would be reported as a 30 per cent $(6 / 20 \times 100)$ change in threshold. After administration of a drug, the frequency of measurements of threshold was determined by the speed of action of the drug, e.g., measurements were made every 5 minutes during an infusion of potassium, and every one-half hour after an injection of aldosterone.

A total of 95 tests was performed on 14 patients, each specific test being run on at least 3 different patients. Twenty-four 
tests were discarded because of nonconformity to the above-mentioned criteria.

\section{Results}

in all tests reported, the variation of threshold was less than 5 per cent over a 30-90-minute control period preceding the test. In 16 patients, threshold was observed under control conditions for 3 to 6 hours, with less than 10 per cent variation in all cases. Setting tolerance limits, we could be 95 per cent confident that 95 per cent of normal cases change 16 per cent or less under control conditions. Thus, for any patient whose threshold varied less than 5 per cent for at least 30 minutes prior to testing, a threshold change of greater than 16 per cent after an experimental procedure was highly significant. Changes in threshold are reported in Tables I-V as plus $(+)$ or minus $(-)$, tepresenting maximal per cent increase or decrease from base-line values.

A. Physiologic studies. Table I shows the results of three different physiologic tests. Sleep appeared to have a profound effect, and in this study resulted in significant (p $<.001)$ threshold elevations of 30 to 10 per cent. With one exception, eating also resulted in a significantly increased threshold $(\mathrm{p}<.001)$. The exception was a patient not kept at a basal level of activity. Physical activity, on the other hand, caused a significant $(p<.001)$ lowering of threshold.

B. Pharmacologic studies. Four classes of pharmacologic agents were tested: electrolytes, sympathomimetic agents, atropine, steroids, and other drugs commonly used in cardiac patients.

1. exectrolytes. Sodium, potassium, valcium, dextrose, and a solution of 40

Table I. Physiologic threshold changes, each measured in 5 patients

\begin{tabular}{l|c|c} 
& $\begin{array}{c}\text { Number of } \\
\text { lesls }\end{array}$ & $\begin{array}{c}\text { Maximal per cent } \\
\text { threshold change }\end{array}$ \\
\hline $\begin{array}{l}\text { Sleeping } \\
\text { Eating }\end{array}$ & 5 & $+38,+36,+41,+36,+30$ \\
Exercise & 5 & $+21,+26,+42,0,+31$ \\
& 5 & $-18,-11,-37,-32,-29$
\end{tabular}

mEq. KCl plus 20 units of regula "sulin: in $1,000 \mathrm{ml}$. of 10 per cent dextrose in water were given in a total of eight different concentrations. The rate of infusion for ach solution is given in Table $\mathrm{TaCl}$ 0.9 per cent) resulted in insignificant changes, whereas 3 per cent $\mathrm{VaCl}$ infused rapidly resulted in very significant $(p<$ $001)$ increases in threshold $(+56,60$, and +56 per cent). In each case, the hy pertonic saline also caused a marked decrease in interelectrode resistance. The solution of potassium and insulin in glucose caused significant $(\mathrm{p}<.01)$ rises in theshold $(+17,+32,+30$, and +13 per cent). Ten per cent dextrose in water had an insignificant effect, and the same was true of a standard solution of $\mathrm{KCl}$ in dextrose $40 \mathrm{mEq}$. of $\mathrm{KCl}$ in $1,000 \mathrm{ml}$. of 10 per cent dextrose in water). When potassium was infused in Ringer's solution, bnwever, it always resulted in a decreased threshold. The equivalent concentration $40 \mathrm{mEq}$. of $\mathrm{KCl}$ in $1,000 \mathrm{ml}$. of Ringer's solution)

Tabie II. Elfect of eleciroivies, repted ts maximal per cent change in threshout changes of 16 per cent or greater are considered to be iignificant)

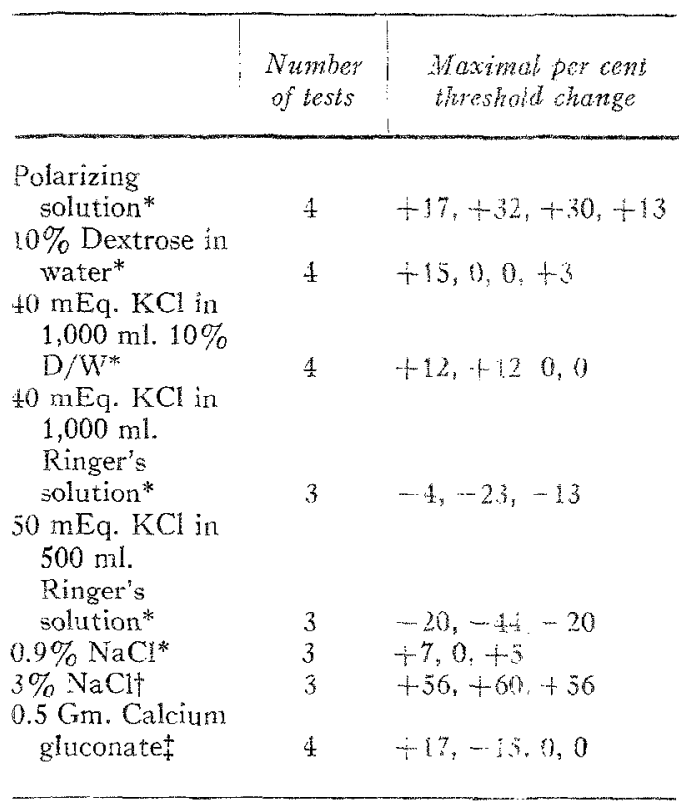

*intravenously, 50 drops per minute.

intravenously, 120 drops per minute.

tintratrenously, given over 5 minutes. 
resulted in changes of $-4,-13$, and -23 per cent, whereas a more concentrated solution $(50 \mathrm{mEq}$. of $\mathrm{KCl}$ in $500 \mathrm{ml}$. of Ringer's solution) yielded more significant $(p<.05)$ decreases $(-20,-20$, and -44 per cent) in 3 cases (see Fig. 1). Ten per cent calcium gluconate, $0.5 \mathrm{Gm}$. given intravenously over 5 minutes, caused no consistent changes. In most cases in which electrolyte solutions did alter threshold, the changes seemed to be transient, reaching a peak and in some cases returning toward the base-line value before the administration of electrolytes was stopped.

2. SYMPATHOMIMETIC AGENTS AND ATROPINE. Table III shows the results of administration of epinephrine, isoproterenol, ephedrine sulfate, and atropine. Atropine had no significant effect on threshold, whereas epinephrine and ephedrine lowered threshold, the effect of epinephrine being more significant $(\mathrm{p}<.05)$. Isoproterenol given intravenously $(1 \mathrm{mg}$. in $250 \mathrm{ml}$. of 5 per cent dextrose in water) caused an initial decrease in 2 of 3 cases, but in all 3 cases the thresholds subsequently increased, to $+56,+80$, and +31 per cent $(\mathrm{p}<.01)$.
3. STERoIDS. Three patients were given intravenous methylprednisolone, and 3 patients were given d-aldosterone (see Table IV), with significant $(\mathrm{p}<.01)$ changes from both drugs. In addition, 10 patients have been given oral prednisone under noncontrol conditions, and this drug always caused decreases in threshold,

Table III. Fiffect of sympathomimetic drugs and atropine

\begin{tabular}{l|c|c}
\hline & $\begin{array}{c}\text { Number } \\
\text { of tests }\end{array}$ & $\begin{array}{c}\text { Maximal per cent } \\
\text { threshold changs }\end{array}$ \\
\hline $\begin{array}{l}\text { Epinephrine, } \\
1: 1000^{*}\end{array}$ & 4 & $-14,-11,-20,-16$ \\
$\begin{array}{l}\text { Ephedrine } \\
\text { sulfate }\end{array}$ & 3 & $-31,0,-16$ \\
$\begin{array}{l}\text { Isoproterenol } \$ \\
\text { Atropine }\end{array}$ & 3 & $+56,+80,+31$ \\
& 3 & $0,+16,0$
\end{tabular}

*0.3 ml. subcutaneously.

$\nmid 25 \mathrm{mg}$. orally.

$\$ 1 \mathrm{mg}$, in $250 \mathrm{ml}$. of 5 per cent dextrose in water, 50 drops per minute.

$\$ 0.4 \mathrm{mg}$. intravenously.

IfAfter initial decrease, threshold rose markedly. See lij. 4.

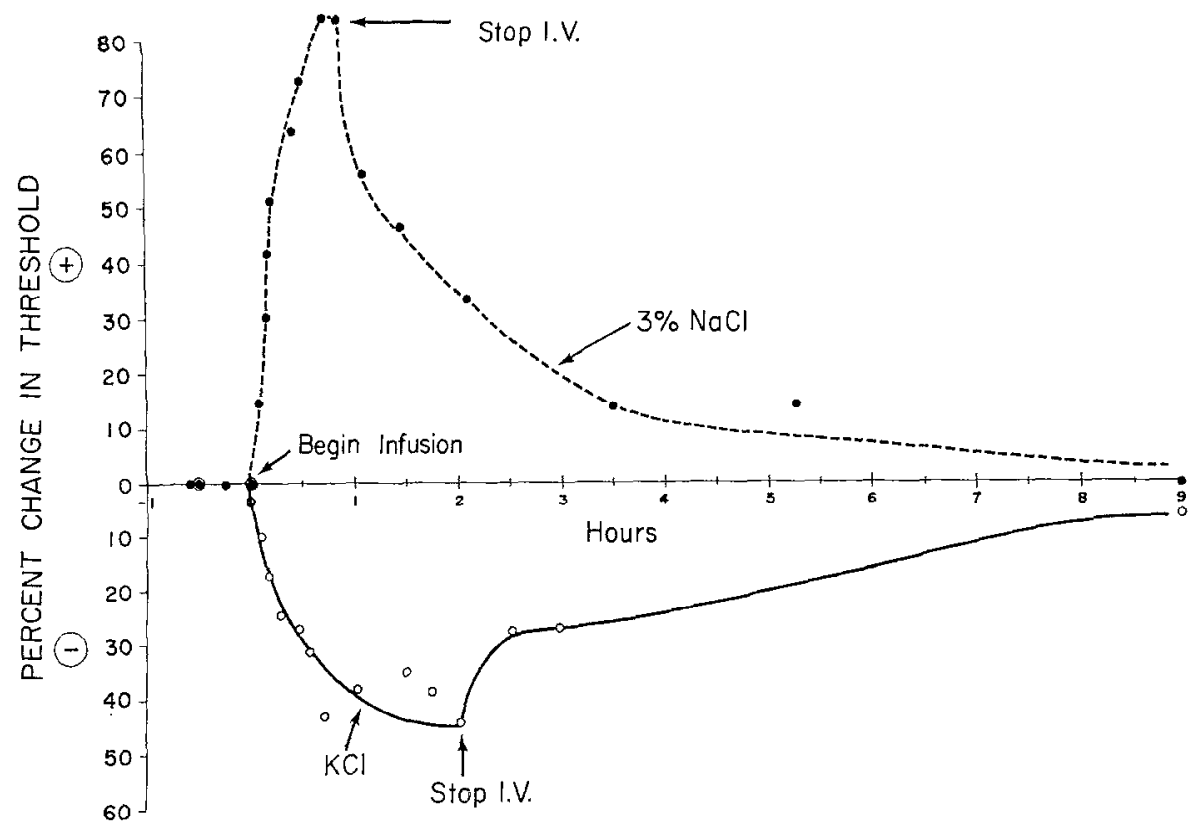

Fig. 1. Threshold changes after infusions of 3 per cent $\mathrm{NaCl}$ and $\mathrm{KCl}$ ( $50 \mathrm{mEq}$. in $500 \mathrm{ml}$. of Ringer's solution). The infusions were in the same patient on different days. The 3 per cent $\mathrm{NaCl}$ was infused at a rate of 120 drops per minute; the $\mathrm{KCl}$, at 50 drops per minute. In each case, threshold remained constant for at least 30 minutes prior to the infusion. 
Table IV. Effect of a potent mineralocorticoid and a potent glucocorticoid, given to 3 patients

\begin{tabular}{l|c|c}
\hline & $\begin{array}{c}\text { Number } \\
\text { of tests }\end{array}$ & $\begin{array}{c}\text { Maximal per cent } \\
\text { threshold change }\end{array}$ \\
\hline $\begin{array}{l}\text { d-Aldosterone, } \\
500 \text { Gm., } \\
\text { intravenously } \\
\text { Methylprednisolone, } \\
40 \text { mg., } \\
\text { intravenously }\end{array}$ & 3 & $+37,+19,+29$ \\
\hline
\end{tabular}

Tavle V. Results of adminisiration of digitalis (lanatoside $C$ ), procaine amide, and morphine

\begin{tabular}{l|c|c}
\hline & $\begin{array}{c}\text { Number } \\
\text { of tests }\end{array}$ & $\begin{array}{c}\text { Maximal per cent } \\
\text { threshold change }\end{array}$ \\
\hline Digitalis* & 3 & $+13,-9,0$ \\
Procaine amidet & 3 & $0,+7,+37$ \\
Worphine & 3 & $-8,-13,0$ \\
\hline
\end{tabular}

*Cedilanid, $0.8 \mathrm{mg}$. intravenousiy. $\$ 800 \mathrm{mg}$, intravenously, in 50 minutes. $\$ 8 \mathrm{mg}$, intramuscularly. the effect being related wo dosage. The rt sults to date indicate that glucoror cicoids decrease, and mineralocorticoids increase, the threshold. Fig. 2 illustrates the opposite effects of these two steroids given to one of the patients.

4. PRONESTYL (PROCAINe AMDE), CEDtLANID (LANATOSIDE C), AND MORPHINE sulfate. Table $V$ shows the resilts of testing with these drugs. Procane amide and lanatoside $C$ had no significant effect. The one rise of +37 per cent with procaine amide came 2 hours after administration of the drug, there being no change in the acute period. Morphine caused no significant changes in threshold.

\section{Discussion}

It is genetally thought that sxcitation of a single myocardial cell, or a syncytium of cells, ${ }^{6}$ is a function of (1) the exciting stimulus, (2) the resting membrane potential, (3) membrane resistance, and (4) the cellular threshold potential. 7-11 For excitation to occur, the exciting stimulus must reduce the resting membrane potential to the level of the cellular threshold potential, at which point the action potential begins. Thus, for a given pacemaker stimulus, within certain limits a reduction of the resting membrane potential of the myocardial colls would theoretically reduce the threshold reguire-

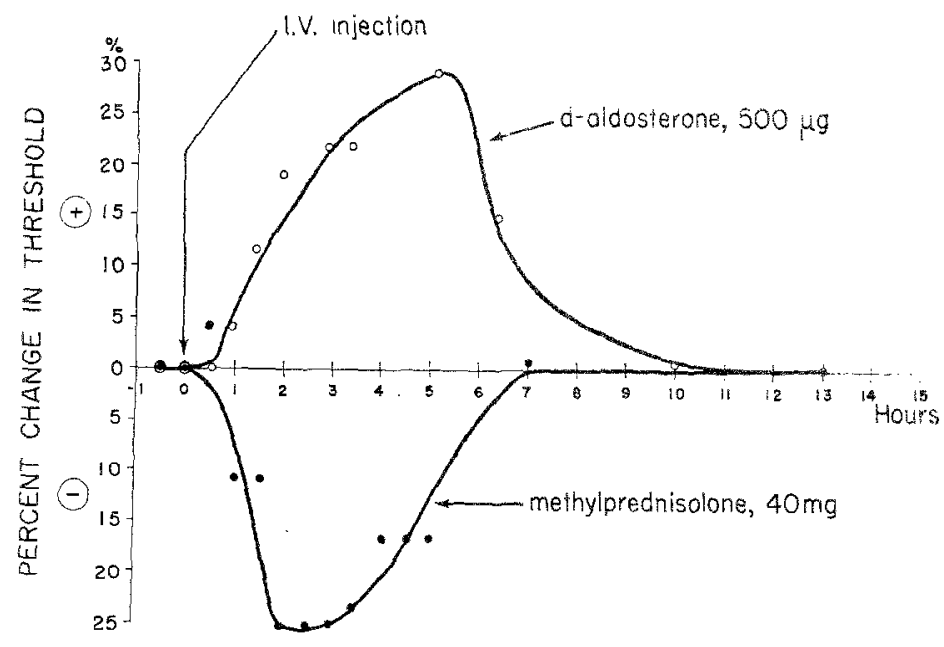

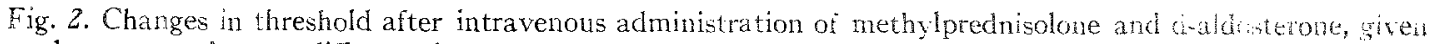
to the same patient on different days. 
ment. An increase in the gap between cellular resting and threshold membrane potentials would increase the myocardial threshold.

Since all patients in this study had their pacemaker electrodes implanted directly in to the myocardium, we assume that the changes demonstrated were due to effects on cells immediately adjacent to the electrodes. However, if the electrodes were implanted deeply enough, there might also be an additional effect mediated by the Purkinje conducting system. It is known that ventricular muscle fibers are relatively insensitive to many agents that have an effect on Purkinje tissue. ${ }^{12}$

Three physiologic variables-sleeping, eating, and exercise-produced significant changes in threshold. We had previously observed, in clinical cases of borderline high thresholds, patients who were not pacing at rest who could be induced to pace by mild exercise. Lowering of threshold secondary to physical activity is presumed to be due to increased sympathetic stimulation. One patient who had been resting comfortably had a sudden attack of acute back pain, and within 5 minutes her threshold dropped 57 per cent.

The significant elevation of threshold accompanied by slceping, or the cating of a large meal, could be attributed to decreased sympathetic tone. We have 2 patients who report having awakened with intermittent pacing, with a return to normal pacing after arising. The effects of exercise, sleeping, and eating account for most of the spontaneous changes in threshold observed. For any patient, these could result in swings of 50 per cent or more during the course of a day. Although emotional factors may well have an additional significant effect on threshold, no altempt was made in the present study to assess this element.

The results of infusion of electrolytes can be classified under three general headings: potassium, sodium, and calcium (see Table II). Electrolyte effects were often transient, returning toward normal before cessation of the infusion in some cases.

Infusions of potassium and insulin in glucose resulted in significant rises in threshold, whereas infusions of 10 per cent dextrose in water with or without potassium caused no significant effect. It is known that insulin increases the uptake of polassium by cardiac muscle, ${ }^{13-15}$ and our findings are consistent with the hypothesis that threshold is increased by increasing the $\mathrm{K}_{\mathrm{i}} / \mathrm{K}_{\mathrm{o}}{ }^{*}$ ratio, thereby increasing the resting membrane potential and the threshold stimulus requirement. We interpret the lack of significant change in threshold in response to solutions of dextrose and potassium without insulin to an absence of significant change in the $\mathrm{K}_{\mathrm{i}} / \mathrm{K}_{0}$ ratio. Measurements of serum potassium during the infusions showed inconstant changes which established no trend. This is similar to the findings of others. ${ }^{14,16}$

In an attempt to increase $K_{0}$ owithout a proportional increase in $K_{i}$, we infused potassium in Ringer's solution (Fig. 1). The results in Table II show significant decreases in threshold by this method, supporting the possibility that the $\mathrm{K}_{i} / \mathrm{K}_{\text {n }}$ ratio was indeed decreased. Walker and associates $^{17}$ have reported increased responsiveness (decreased threshold) to an implanted pacemaker after the administration of oral potassium, the mechanism presumably being an increase in $K_{0}$ in relation to $K_{i}$.

The striking cffect of concentrated solutions of $\mathrm{NaCl}$ in raising threshold (see Table I) varies from reports that the sodium ion has no effect on cellular excitability. ${ }^{7}$ The high concentrations of $\mathrm{NaCl}$ used in this study may have resulted in shifts in potassium. The ancillary finding of a marked lowering of interelectrode resistance ${ }^{1}$ with 3 per cent saline is probably a result of increased conduction between the electrodes, secondary to hypertonicity of the extracellular medium. It is conceivable that this shunts current past the myocardial cells, thereby increasing the stimulus necessary for excitation.

We found no consistent changes after the intravenous administration of 0.5 $\mathrm{Gm}$. of calcium gluconate, but it is possible that larger doses might have had an effect. ${ }^{7,12,18,19}$

The results with standard clinical doses

${ }^{*} \mathrm{~K}_{\mathrm{i}}=$ Intracellular potassium. $\mathrm{K}_{0}=$ Extraceltular potassium. 
of the zympathomimetic agents, epinephrine and ephedrine, showed a lowering of inyocardial threshold. Hoffman and Cranehield ${ }^{i}, 12$ state that epinephrine has very little effect on the resting membrane porential of $\mathrm{dng}$ or cat ventricular fibers, but it may lower the threshold of Purkinje fibers by increasing the membrane threshold potential. It is conceivable, therefore, that the effect of sympathomimetic agents on the responsiveness to an implanted pacemaker may depend in part on how close the electrodes are to the Purkinje system. Isoproterenol infused rapidly (see Fig. 3) caused, first, a lowering of threshold, and then a marked elevation of threshold. This is similar to findings in logs reported by Siebens and co-workers. ${ }^{20}$ it is possible that this is a dose-related thenomenon, and that a smaller dose would produce a persistently decreased breshold.

The finding that a glucocorticoid, methylprednisolone, significantly lowers threshold, whereas a potent mineralocorticoid, aldosterone, significantly elevates threshold, fits with the authors' clinical imgression that glucocorticoids increase esponsiveness to a pacemaker, and mineralocorticoids have the opposite effect. We have monitored the thresholds of 10 patients treated with prednisone and have ound a marked reduction of threshold in all of them.

The mode of action of steroids is uncertain. Perhaps steroids affect threshold because of their infuence on the porrech bility of the cell membrane. if such were the case, one would have to assime opposing effects of glucorcorticoids und mineralocorticoids at the cellular level, with the former decreasing and the latter increasing the permeability to potassium. The final effect on threshold would then be mediated by an altered resting membrane potential. Modification of the sodium-potassium relationships could also result in alteration of the cellular threshold potential. Aber and Jones ${ }^{21}$ report large inverted $T$ waves and $Q-T$ prolongation during treatment with glucocorticoids, which findings they think smport the concept that steroids interfere with the sodium-potassium pump across the cull nembrane. Another explanation for the effect of steroids on threshold is their known potentiation of catecholamines.

In our studies, digitalis and quinidine caused no significant changes in threshold, although variable effects have been reported from microelectrode studies. ${ }^{7,22}$ One of our patients had multiple ecropic ventricular beats competing with his electronic pacemaker. The administration of procaine amide to this patient resulted in complete disappearance of the ectopic beats, but it caused no change in the threshold to stimum lation by the electronic pacemaker. This finding shows the disparity between automaticity and responsiveness to electrical stimulation.

This investigation has demonstrated

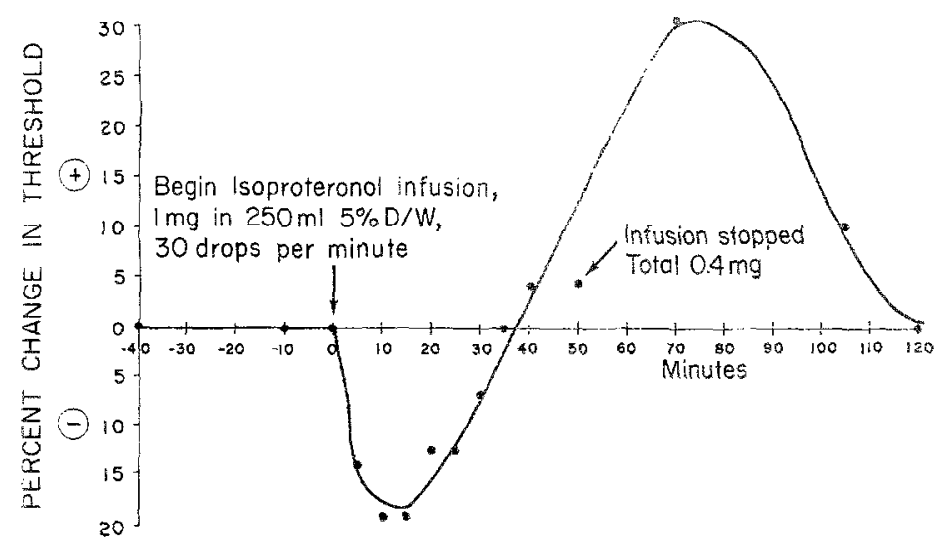

Fig. 3. Fffect of intravenous isoproterenol, which caused initial decrease in theshold, and ina fevatron of threshold. 
the lability of myocardial threshold in man, and the susceptibility of threshold to manipulation by physiologic activities and pharmacologic agents. Although of uncertain clinical usefulness, these findings may be of benefit in cases in which it is desirable to alter responsiveness to electrical stimulation.

\section{Summary}

Seventy-one controlled threshold studies were performed on 14 patients with implanted cardiac pacemakers.

Eating and sleeping raised myocardial threshold significantly, whereas exercise had a reverse effect. A solution of insulin and potassium in dextrose, 3 per cent $\mathrm{NaCl}$, and aldosterone also increased threshold. Epinephrine, methylprednisolone, and potassium chloride in Ringer's solution lowered threshold. Isoproterenol caused an initial fall in threshold, followed by a marked rise. No significant changes were demonstrated with 10 per cent dextrose, normal saline, calcium gluconate, lanatoside $\mathrm{C}$, procaine amide, atropine, or morphine at those dosages that were arbitrarily chosen for this study.

The results demonstrate that myocardial threshold in man is labile, and that it can be manipulated by physiologic activities and pharmacologic agents.

\section{REFERENCES}

1. Preston, T. A., Judge, R. D., Bowers, D. L., and Morris, J. D.: Measurement of paccmaker performance, АM. HearT J. 71:92, 1966.

2. Preston, T. A., Judge, R. D., Lucchesi, B. R., and Bowers, D. L.: Myocardial threshold in patients with artificial pacemakers, Am. J. Cardiol. $18: 83,1966$.

3. Dekker, E., Büller, J., and Van Erven, F. A.: Unipolar and bipolar stimulation thresholds of the human myocardium with chronically implanted pacemaker electrodes, AM. HEART J. $71: 671,1966$.

4. Albert, H. M., Glass, B. A., Pittman, B., and Robichaux, P.: Cardiac stimulation threshold: Chronic study, Ann. New York, Acal. Sc: 111:889, 1964 .

5. Davies, J. G., and Sowton, E.: Electrical threshold of the human heart, Brit. Heart J. 28:231, 1966.
6. Ling, G., and Gerard, R. W.: Normal membrane potential of frog sarturius fibers, J. Cell. Cornp. Physiol. 34:383, 1949.

7. Hoffman, B. F, and Cranefield, P. F.: Electrophysiology of the heart, New York, 1960, McGraw-Hill Book Company, Inc.

8. Hoffman, B. F.: Impulse transmission in the mammalian heart, American Heart Association Monograph, No. 9, II-202, 1964.

9. Hodgkin, A. L., and Horowicz, P.: The influence of potassium and chloride ions on the membrane potential of single muscle fibers, J. Physiol. $148: 127,1959$.

10. Reynolds, E. W.: Ionic transfer in cardiac muscle. An explanation of cardiac electrical activity, Am. HEART J. 67:693, 1964.

11. Robertson, W., and Dunihue, F. W.: Water and electrolyte distribution in cardiac muscle, Am. J. Physiol. 177:292, 1954.

12. Hoffman, B. F., and Cranefield, P. F.: The physiological basis of cardiac arrhythmias, Am. J. Med. $37: 670,1964$.

13. Goodman, L. S., and Gilman, A.: The pharmacological basis of therapeutics, New York, 1965, The MacMillan Company.

14. Sodi-Pallares, D., Testelli, M. R., Fishleder, B.L., Bisteni, A., Medrano, A., Friedland, C., and DeMicheli, A.: Effects of an intravenous infusion of a potassium-glucose-insulin solution on the electrocardiographic signs of myocardial infarction, Am. J. Cardiol. 9:166, 1962.

15. Zierler, K. L.: Increase in resting membrane potential of skeletal muscle produced by insulin, Science 126:1067, 1957.

16. Sodi-Pallares, D., Bisteni, A., Medrano, G. A., Testelli, M. R., and DeMicheli, A.: The polarizing treatment of acute myocardial infarction, Dis. Chest. 43:424, 1963.

17. Walker, W. J., Elkins, I. T., and Wood, L. W.: Effect of potassium in restoring myocardial response to a subtreshold cardiac pacemaker, New England J. Med. 271:597, 1964.

18. Weidmann, S.: Effects of calcium ions and local anesthetics on electrical properties of Purkinje fibers, J. Physiol. 129:568, 1955.

19. Brink, F.: The role of calcium ions in neural processes, Pharmacol. Rev. 6:243, 1954.

20. Siebens, A. A., Hoffman, B. F., Enson, Y., Farrell, J. E., and Brooks, C. M.: Effects of l-epinephrine and 1-norepinephrine on cardiac excitability, Am. J. Physiol. 175:1, 1953.

21. Aber, C. P., and Jones, E. W.: Steroid-induced T wave changes in heart biock, Brit. Heart J. $27: 56,1965$.

22. Johnson, E. A.: The effects of quinidine, procaine anide, and pyrilamine on the membrane resting and action potential of guinea pig ventricular muscle fibers, J. Pharmacol. \& Exper. Therap. 117:237, 1956. 